\title{
INFLUENCIA DE LAS EMISIONES DEL TRÁFICO EN LA PATOLOGÍA DEL ARBOLADO ANEJO A LAS CARRETERAS
}

\author{
(INFLUENCE OF TRAFFIC POLLUTION ON VEGETATION \\ PATHOLOGIES)
}

José A. Sáiz de Omeñaca, Ascensión Alfaro, José A. Rodríguez Barreal y Jesús Sáiz de Omeñaca*

\section{RESUMEN}

Se repasan las patologías que más frecuentemente afectan a la vegetación como consecuencia de la inmisión de contaminantes generados por la circulación de automóviles y se expone brevemente un caso concreto.

\section{SUMMARY}

This paper summarizes the information on more frequent vegetation pathologies as consequence of immisission of traffic-born pollutants. A case study is briefly exposed.

\section{INTRODUCCIÓN}

El conocimiento y control de las perturbaciones provocadas directa o indirectamente en el medio natural por diversas actividades humanas, así como, en su caso, la recuperación del mismo, son de obligado cumplimiento según lo dispuesto en el Real Decreto Legislativo 1302/1986, de Evaluación del Impacto Ambiental y en su correspondiente Reglamento (aprobado por Real Decreto 1131/88). El Apartado 7 del anexo al Real Decreto primeramente citado incluye a las carreteras entre las acciones que requieren Evaluaciones del Impacto Ambiental, y en el Artículo 8 del Reglamento se trata de las emisiones permanentes durante la fase de explotación u operación, es decir, la contaminación producida por la circulación en las carreteras. El efecto de tales emisiones sobre la vegetación no se menciona, sin embargo, en el Manual de plantaciones en el entorno de la carretera editado por el Ministerio de Obras Publicas y Transportes (5).

\footnotetext{
* Departamento de Silvopascicultura (Escuela T.S. de Ingenieros de Montes) de la Universidad Politécnica de Madrid. 28040 Madrid, España.
}

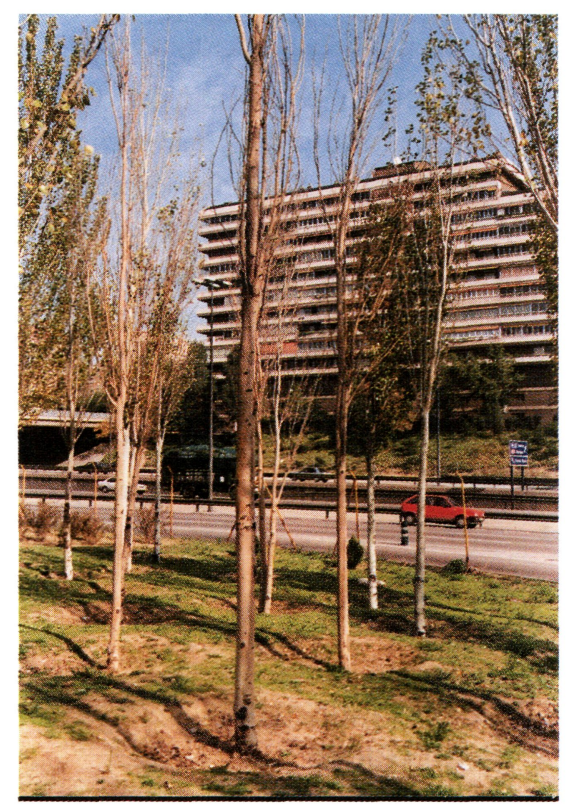

En algunas zonas se ha pretendido crear barreras vegetales mediante plantaciones de chopos. Las deficientes condiciones de crecimiento y la elevada densidad de la ptantación favorecen frecuentemente la muerte de los árboles, tal como ba ocurrido con el que aparece en primer termino. 


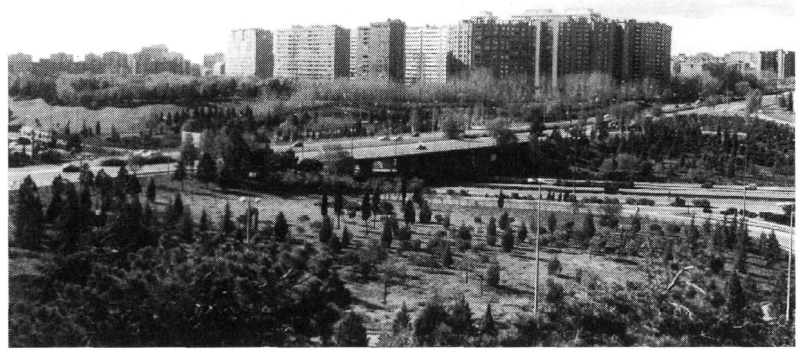

Los alrededores de la $M-30, y$ particularmente en las intersecciones con otras vias han sido ajardinados en su mayoría y disponen por tanto de la correspondiente vegetación arbórea. Se trata, casi siempre, de árboles jóvenes o muy jóvenes, en pleno vigor vegetativo, por lo que el decaimiento o la presencia de plagas y enfermedades es achacable a factores ambientales.

El tránsito puede provocar la inclusión, en el medio ambiente y en la propia vegetación arbórea próxima a los viales, de diversas sustancias químicas y partículas e incluso de algunos microorganismos y sustancias radiactivas; es decir, de contaminantes. El movimiento de los automóviles provoca emisiones de los motores y desplazamientos de partículas que tienen como consecuencia la presencia en el medio natural de productos muy escasos o ajenos a él: óxidos de azufre, de nitrógeno y de carbono, hidrocarburos, partículas sólidas (que frecuentemente contienen metales pesados), etc. La acción de tales contaminantes sobre los vegetales depende, entre otros factores, de la peculiar organización de éstos (organismos fotosintetizadores con transporte de sustancias por floema y xilema y circulación de gases a través de estomas, carencia de un sistema excretor pero presencia de vacuolas celulares, células provistas de pared celular con plasmodesmos, etc.) y de su carácter sésil. Conviene recordar, además, que resulta ingenuo creer que la presencia o mayor disponibilidad de algunos contaminantes, y más concretamente de $\mathrm{CO}_{2}$, resulte beneficiosa para la vegetación (6).

\section{EFECTOS DE CONTAMINANTES SOBRE LA VEGETACIÓN}

La mayor parte de los contaminantes afectan al suelo y el primer nivel de respuesta de los vegetales está en la raíz y en las micorrizas, formas especiales de simbiosis entre el aparato radicular de las plantas y algunos hongos que viven en el suelo. La formación,

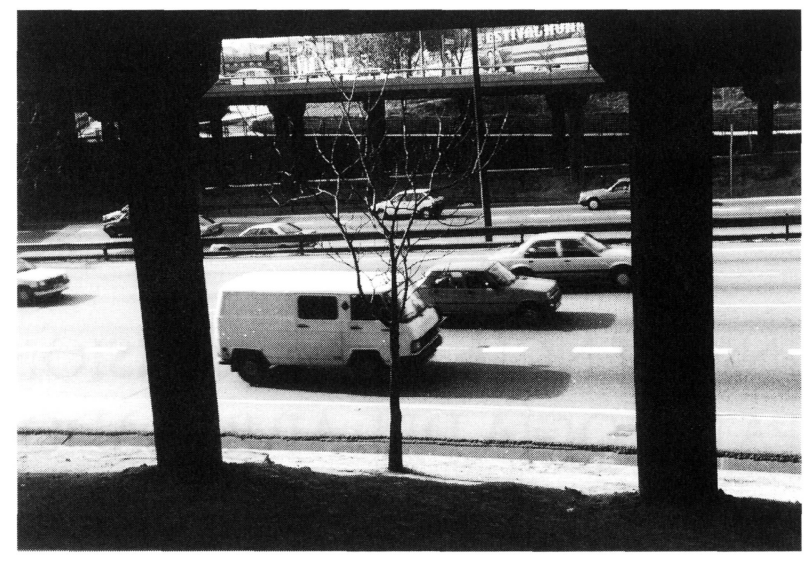

Las condiciones ambientales en las que se pretende el desarrollo de la vegetación no son las idóneas y pueden llegar a ser realmente duras. A la contaminación del aire y del suelo, se añaden la compactación del suelo, la limitación en las disponibilidades de agua $y$ de luz, el aumento de temperatura debido a la insolación de la superficie de rodadura y las vibraciones ocasionadas por el paso de vebiculos. En la fotografía, la ausencia de vegetación herbácea indica lo extremado de las condiciones.

desarrollo y mantenimiento de la simbiosis micorrícica resulta afectada por diversos contaminantes $(2,8)$. Generalmente, las raíces afectadas por contaminantes muestran menores crecimientos, por lo que puede observarse una caída en la relación entre raíz y parte aérea, con los consiguientes efectos sobre las tasas de transpiración y otras (12).

\section{GASES CONTAMINANTES}

Los óxidos de nitrógeno y de azufre, que en absoluto se forman exclusivamente en los motores de los automóviles, se transforman en ácidos nítrico, sulfuroso y sulfúrico por la presencia de cierto grado de humedad ambiental. Conjuntamente con el cloro, responsable de la formación de ácido clorhídrico, son subproductos de procesos industriales o domésticos; todos ellos se originan, generalmente, por combustiones, pueden ser trasladados a grandes distancias (a veces, hasta $2.000 \mathrm{~km}$ ), y originar la llamada lluvia ácida: precipitación acuosa con un pH frecuentemente menor de 4 (y no es raro que llegue incluso a 3) pero en todo caso inferior al normal en el agua de lluvia, el cual es de 5,7. El efecto de la lluvia ácida sobre los sistemas forestales, la calidad del agua y los agrosistemas de países industrializados, o no industrializados, situados a sotavento, se considera cada día más importante $(10,12)$, pero la misma movilidad de estos contaminantes es la razón por la que el arbolado anejo a las carreteras no resulta afectado de forma específica (13). Existen métodos que permiten establecer las consecuencias sobre la vegetación, incluso a largo plazo $(4,7)$. 


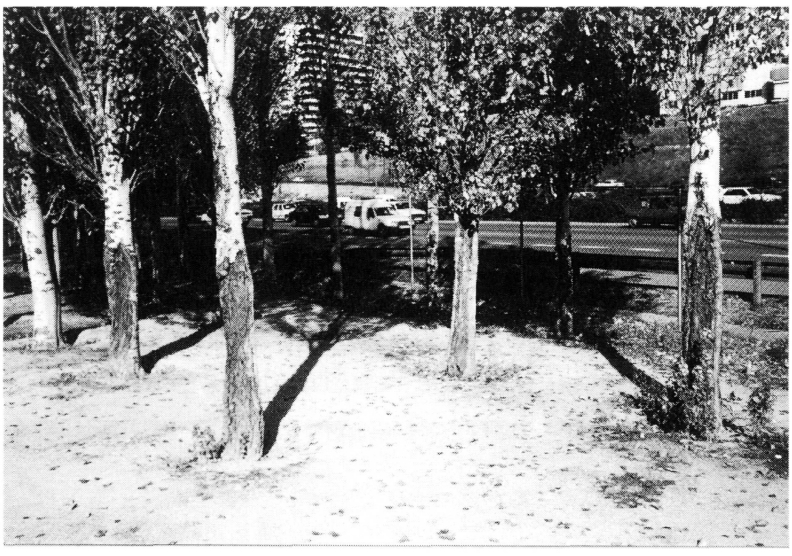

Las malas condiciones de vegetación y la insolación sufrida por los troncos ocasionaron daños, orientados hacia el suroeste, en la corteza de los álamos de la fotografía; tras Cytospora chrisosperma, hongos de pudrición como Schizophillum commune e insectos xilófagos afectaron a la madera de los fustes. Los rebrotes que pueden observarse al pie de algunos ejemplares aparecen como respuesta del árbol a tal situación.

El más importante de los óxidos de nitrógeno y de azufre, desde el punto de vista de sus consecuencias perniciosas sobre la vegetación, es el anhídrido sulfuroso (1), $\mathrm{SO}_{2}$, que mediante la adición de agua se transforma en ácido sulfuroso, $\mathrm{SO}_{3} \mathrm{H}_{2}$. Es un residuo de la combustión de los carburantes utilizados en automoción o de otros combustibles, que penetra fácilmente hasta el mesófilo gracias a que los estomas se abren cuando aumenta la luz y la humedad atmosférica e incluso ante la presencia de dosis no demasiado elevadas de anhídrido sulfuroso. Las secuelas varían según la especie vegetal, el medio edafoclimático, la presencia o ausencia de otros contaminantes atmosféricos (ozono, óxidos de nitrógeno, etc.) y la exposición (crónica o aguda). En las hojas de los árboles muy expuestos a este contaminante pueden apreciarse necrosis en el mesófilo, desintegración de orgánulos celulares y plasmólisis y muerte de las células afectadas, con las consiguientes clorosis, necrosis marginales e intercostales en las hojas tiernas y, también, en ápices, flores y frutos (3); no se conocen suficientemente, sin embargo, los efectos del anhídrido sulfuroso sobre las raíces de las plantas. Es conocido incluso a nivel popular que distintos líquenes muestran una gran sensibilidad al $\mathrm{SO}_{2}$, variable entre unos y otros, por lo que su presencia sobre las ramas de los árboles u otros sustratos puede ser utilizada como indicadora del grado de contaminación por anhídrido sulfuroso.

El ozono es un contaminante que aparece como consecuencia de actividades industriales, domésticas y de automoción, pero su fácil difusión en las capas atmosféricas más bajas dificulta que produzca daños en el arbolado cuando el tránsito de automóviles es

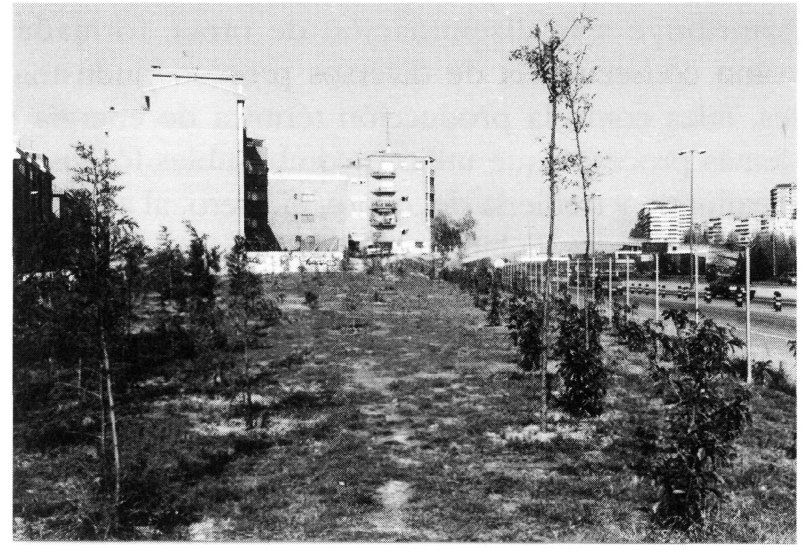

Las plantaciones precisan un minimo de cuidados culturales, sobre todo durante los primeros años de vida, para evitar daños y malformaciones. La falta de tales cuidados, en tiempo y forma, es habitual.

la única fuente de ozono. La vegetación afectada por exceso de ozono muestra, además de perturbaciones funcionales en las células oclusivas de los estomas (pérdida de turgencia y los consiguientes cierre, caída de la transpiración y de la respiración), alteraciones en el funcionamiento de las membranas celular y de orgánulos (por ejemplo, en los cloroplastos y, por tanto, en la fotosíntesis) e interferencias en el metabolismo de proteínas e hidratos de carbono (12). La sintomatología de daños por exceso de ozono incluye la aparición, preferentemente en hojas ya maduras, de manchas oleosas, manchas que tienden a aumentar de tamaño y a dar origen a zonas marchitas o necróticas.

Mayor importancia, en el entorno de las carreteras, debe concederse al nitrato de peroxiacetilo (PAN) y a algunas sustancias análogas que proceden de reacciones en la atmósfera tras la liberación de diversos compuestos procedentes de procesos industriales y del funcionamiento de motores. Causan el hinchamiento de las células oclusivas de los estomas, particularmente en hojas jóvenes, y el colapso de células epidérmicas, además de alteraciones en los sistemas de membranas celulares (al menos en las células del mesófilo) y en diversas rutas metabólicas.

\section{PARTÍCULAS SÓLIDAS Y ELEMENTOS QUÍMICOS}

El desgaste de los frenos y de las cubiertas de los neumáticos, entre otras causas, provoea la aparición de diversos tipos de partículas sólidas, pero el tránsito de vehículos, además de generar tales partículas, 
contribuye a la diseminación de otras, formadas como consecuencia de diversos procesos industriales, tales como la producción térmica de energía y demás procesos que utilicen combustibles fósiles, la metalurgia y trefilería del cobre, el acero, al aluminio y las aleaciones, la fabricación de biocidas, de plásticos y cementos, la extracción de áridos o la realización de algunas actividades domésticas (13); las partículas generadas en tales procesos se añaden al polen, esporas de hongos y bacterias y otras de origen orgánico.

En la composición de las partículas sólidas figuran diversos metales pesados, es decir, metales cuyo peso específico es superior a $5 \mathrm{~g} / \mathrm{cm}^{3}$, entre ellos cobre, cinc, cadmio, plomo, mercurio y aluminio, así como sales de los mismos. Los metales pesados, que son raros en estado natural, son potencialmente tóxicos para los vegetales, aunque la susceptibilidad de éstos es variable, y no sólo según las especies afectadas, sino también entre variedades o genotipos diferentes, como corresponde a algo tan heterogéneo como los metales pesados y las diversas interacciones posibles con los diversísimos compuestos orgánicos presentes en las células.

Cabe señalar que los metales pesados están mejor estudiados, en cuanto a su presencia en el suelo, que otros contaminantes. Las plantas, como organismos productores que son, forman un primer eslabón en las cadenas tróficas de los ecosistemas; son organismos que tienen un contacto más directo, más abierto y más limitado con su medio (tanto atmosférico como edáfico) que los animales. Cualquier variación negativa es causa de estrés físico (falta o exceso de luz, temperatura inadecuada, cambios osmóticos, etc.), químico (falta o exceso de nutrientes u otros iones, cambios en la salinidad) o biológico (infecciones por hongos, bacterias, virus u otros organismos, desarrollo de plagas). En cuanto a los metales pesados, es un hecho bien conocido que su concentración suele ser mayor en la raíz que en su medio circundante. Un segundo nivel de respuesta se halla en tallos y hojas y puede ocasionar problemas graves en cloroplastos y mitocondrias o, en general, en membranas (muy afectadas tras la formación de radicales libres). Se estimula la senescencia (que puede llegar a manifestarse en la muerte de hojas u otros órganos o de la planta completa) y se altera el metabolismo de nutrientes y diversos metabolitos.

Los elementos químicos, respecto a los vegetales, pueden clasificarse en esenciales, beneficiosos, tóxicos e indiferentes o de acción desconocida. Debe tenerse en cuenta, sin embargo, que tanto los elementos esenciales como los beneficiosos se convierten en tóxicos cuando se alcanzan concentraciones superiores a un determinado umbral. Los elementos que son esenciales, tóxicos, etc. para las plantas, no siempre tienen el mismo carácter para los animales: el cromo es esencial para el hombre y los animales superiores, pero no parece serlo para las plantas; el silicio es esencial para los vertebrados y para las gramíneas, pero no para otros grupos de animales o plantas, etc.

Son elementos esenciales aquellos que la planta necesita, sin que puedan ser sustituidos por otros, para el correcto desenvolvimiento de procesos metabólicos y de regulación, crecimiento y desarrollo incluidos. Tienen el carácter de esenciales el carbono, el hidrógeno, el oxígeno, el nitrógeno, el azufre, el fósforo, el potasio, el calcio, el magnesio, el hierro, el manganeso, el cobre, el cinc, el molibdeno y el cloro; algunos otros pueden ser esenciales para determinadas plantas, como el níquel lo es para las leguminosas. Son elementos beneficiosos aquellos que estimulan el crecimiento y el desarrollo de los vegetales, dependiendo de factores ambientales y con una amplia variación según la especie de que se trate: son el níquel, el cromo, el sodio, el silicio, el vanadio, el cobalto y otros. Los elementos tóxicos son aquellos que, incluso en concentraciones mínimas, impiden o dificultan gravemente ciertos procesos importantes; es el caso del cadmio, el plomo, el mercurio, el uranio y otros. Cada elemento tóxico actúa de una forma determinada o en determinados niveles (molecular, membrana celular, pared celular, distintos orgánulos, etc.) y resulta difícil distinguir entre niveles primarios (proteínas funcionales en membranas celular o de orgánulos, por ejemplo) y secundarios. Son innumerables los ligandos con los que pueden formarse complejos estables y, como consecuencia, también lo son las alteraciones de procesos catalíticos, las variaciones en la movilidad o las posibilidades de secuestro en algún orgánulo celular. Además, cualquiera de los elementos puede participar en alguna forma de alteración en el sistema de transducción de señales, con las consiguientes modificaciones en las pautas de crecimiento y desarrollo, en la distribución y balance de nutrientes, en la economía hídrica de la planta y en los ajustes osmóticos y metabólicos, en las respuestas a reguladores de crecimiento, etc. Desde un punto de vista fisiológico, en definitiva, los metales pesados distan de ser un grupo homogéneo.

Los vegetales presentan mecanismos de respuesta y defensa muy heterogéneos ante la presencia de ele- 
mentos tóxicos en el suelo. Los más estudiados han sido, por varias razones, los siguientes:

* plomo, cadmio y aluminio, por ser muy tóxicos;

* cromo, por dar respuestas muy diferenciadas;

* cinc, por ser un elemento esencial;

* los elementos radiactivos, por serlo y por su elevado peso atómico.

No suele ser demasiado conocido que existan mecanismos genéticos de adaptación selectiva a concentraciones altas de algunos elementos. No obstante, para operar sobre especies de ciclo vital tan largo como los árboles, precisarían tiempos de actuación considerablemente mayores. Además, algunos casos citados como adaptación selectiva pueden ser debidos a la colonización por micorrizas.

\section{PÉRDIDAS CAUSADAS POR LA CONTAMINACIÓN}

Aunque se han propuesto fórmulas de evaluación de daños resulta difícil, en general, cuantificar las pérdidas causadas en el arbolado anejo a las carreteras por contaminación debida a la circulación de vehículos automóviles, pues el uso de tales fórmulas exige el conocimiento de datos poco accesibles y la realización de análisis más o menos complejos; por ejemplo, para determinar exceso de plomo u otros metales pesados. En todo caso, la variabilidad del tráfico, la topografía, la incidencia de factores meteorológicos y otras variables incrementan la dificultad de determinación cuantitativa de los efectos negativos. Son indicativos de pérdidas la vegetación difícil o no desarrollada con todas sus posibilidades, la presencia superior a lo normal de plagas y enfermedades, la aparición de deficiencias en la nutrición mineral (frecuentemente debidas a interacciones causadas por elementos presentes en concentraciones anormalmente altas) y el descenso en la abundancia de especies herbáceas y arbustivas acompañantes en zonas próximas a las carreteras, cuando se compara con la propia de zonas homólogas alejadas de ellas.

\section{PATOLOGÍA ARBÓREA EN EL ENTORNO DE LA} AVENIDA DE LA PAZ (MADRID)

Se ha determinado la situación fitopatológica del arbolado situado en las proximidades de la autovía

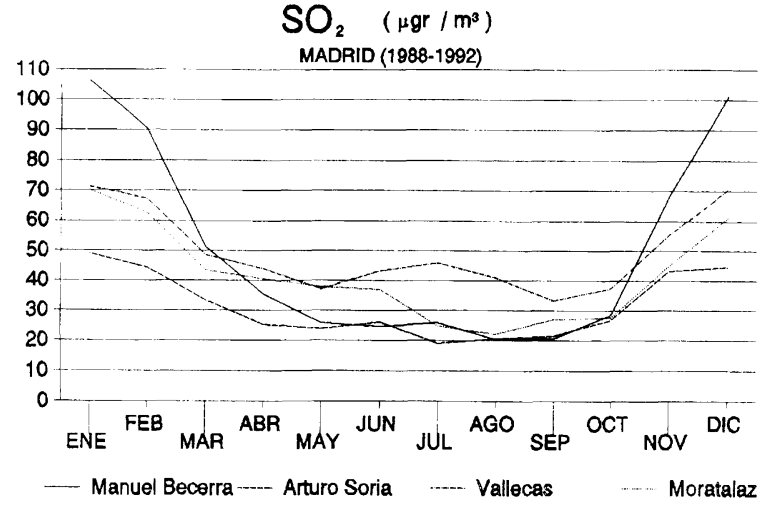

Fig. 1. Variación a lo largo del año de la cantidad de anbidrido sulfuroso, según mediciones efectuadas por las estaciones más cercanas a la Avenida de la Paz.

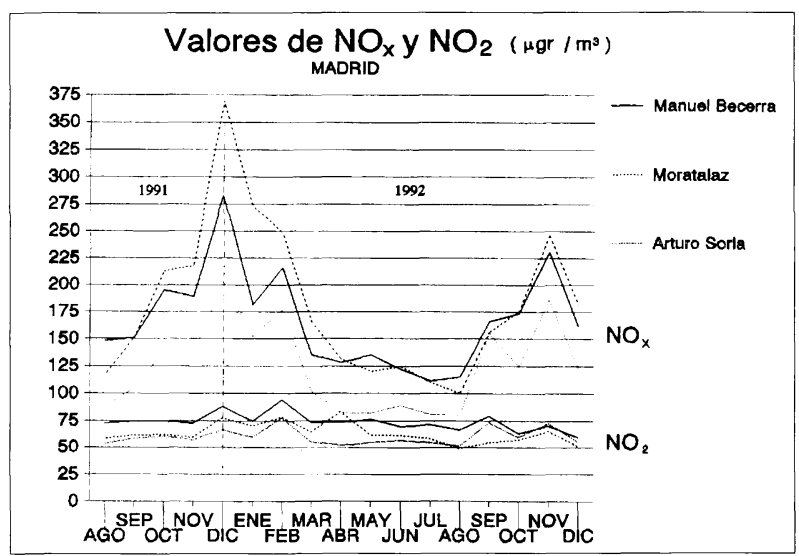

Fig. 2. Variación a lo largo del año de las cantidades de óxidos de nitrógeno ( $\mathrm{NO}_{\mathrm{N}} \mathrm{NO}$,), según las mediciones efectuadas por las estaciones de Manuel Becerra, Moratalaz y Arturo Soria. Tanto en el presente caso como en el ilustrado por las figuras 1, y 4, las emisiones máximas coinciden con la del año en la que los árboles de hoja caediza están desprovistos de follaje.

M-30 (Avenida de la Paz) en el tramo comprendido entre el acceso a la calle de Costa Rica y el de la Avenida del Mediterráneo, ambos incluidos, así como los de O'Donnell y de Avenida de América y los parques Félix Rodríguez de la Fuente, Breogán, Antonio Pirala, Fuente del Berro, Sancho Dávila, Roma y de la Estrella. La zonificación se realizó considerando como alineaciones los espacios entre nudos de la vía de comunicación y como masas arboladas los parques y las áreas correspondientes a los accesos. El inventario botánico y fitopatológico de especies arbóreas se efectuó, pie a pie, entre los meses de septiembre y octubre de 1992. Existían un total de 18.675 árboles, que se clasificaron según especies y clases diamétricas y de los que 4.551 se hallaban en alineaciones, 7.071 en accesos y 7.043 en parques. 


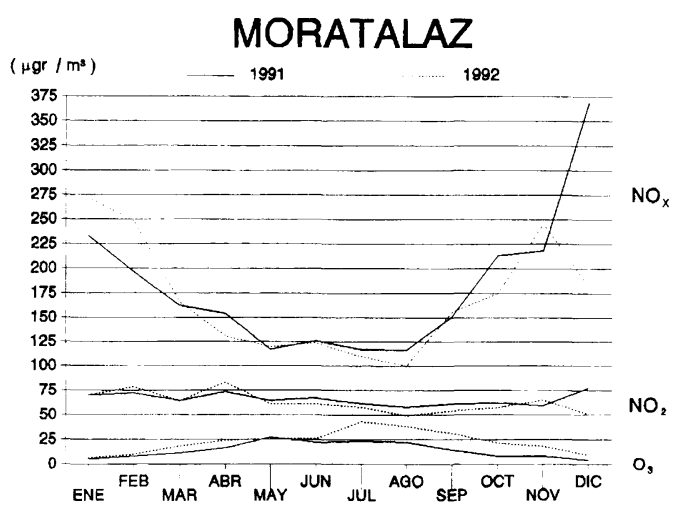

Fig.3. Variación a lo largo del año de las cantidades de óxidos de nitrógeno y de ozono según mediciones efectuadas por la estación de Moratalaz durante dos años consecutivos. Puede observarse la práctica desestacionalidad en lo que se refiere a ozono y $\mathrm{NO}_{2}$

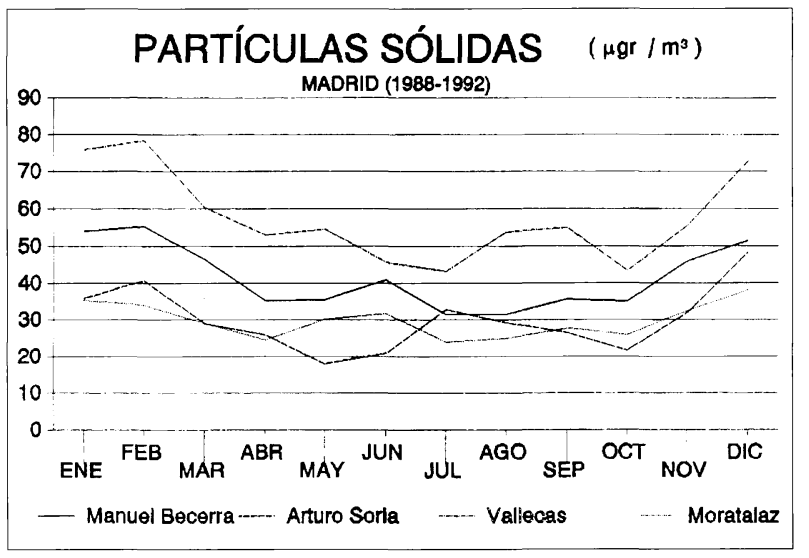

Fig.4. Variación a lo largo del año de la cantidad de partículas sólidas en el aire. según mediciones de las estaciones más próximas a la Avenida de la Paz.

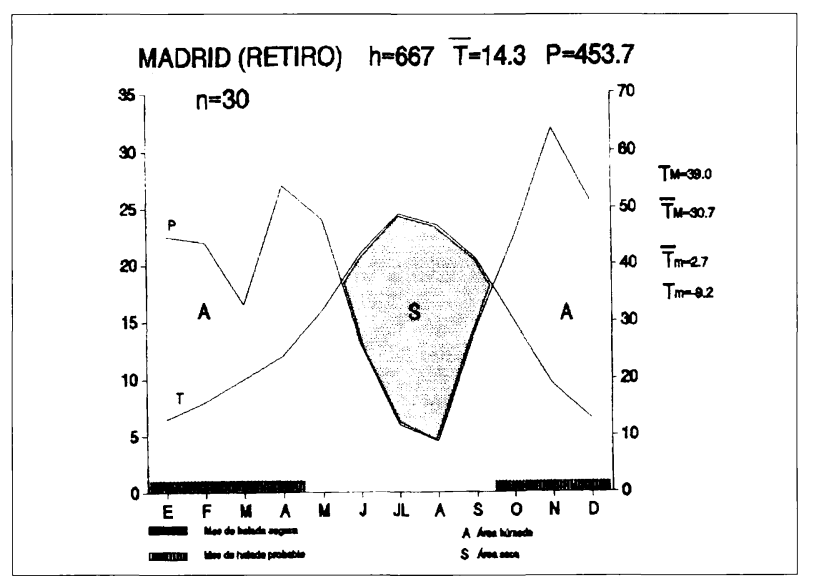

Fig. 5. Diagrama bioclimático, según datos de la estación meteorológica del Parque del Retiro de Madrid.
Puede conocerse el grado de presencia de contaminantes en la zona mediante los datos suministrados por las correspondientes estaciones de medida más cercanas a la zona. Con tales datos se han elaborado las figuras 1, 2, 3 y 4 . La variación a lo largo del año de las condiciones meteorológicas para la vegetación pueden verse en la figura 5 .

Las malas condiciones ambientales (sequía, suelos compactados, contaminación) no suelen provocar la muerte de los árboles (aunque la sequía ha causado la muerte de varios ejemplares de Salix babilónica), pero contribuyen a la disminución de su vigor vegetativo y los predisponen a sufrir plagas y enfermedades:

* cochinillas (homópteros, cóccidos) sobre tallos y hojas de chopos, principalmente en ramillas jóvenes, de pinos y de cedros;

* hemípteros (fíngidos) sobre pinos, en los que se provoca un ligero descortezamiento en ramas y tron$\mathrm{co}$, lo que ocasiona un color asalmonado en los mismos;

* cercópidos sobre ramas y hojas de chopos;

* el hongo Cytospora chrysosperma provoca muy frecuentemente una micosis sobre ramas y tronco de los chopos. En el parque Rodríguez de la Fuente, por ejemplo, estaban secos 26 pies y otros 45 pueden secarse próximamente, de entre 120 enfermos (foto 1). En el parque Sáncho Dávila están enfermos el $90,8 \%$ de los chopos, y el $19 \%$ de ellos sufre daños graves;

* fumaginas en hojas y ramillas de pinos y otras coníferas; los pinos de Monterey aparecen particularmente afectados por la contaminación y sus secuelas, tal como puede apreciarse por la conformación de las copas y otros detalles. El depósito de partículas, además de las fumaginas en las coníferas, es el responsable del ennegrecimiento de los vegetales;

* hongos del género Seiridium provocan el chancro del ciprés en árboles del género Cupressus;

* diversos hongos ocasionan pudriciones en los árboles: Inonotus hispidus, Laetiporus sulphureus, Stereum hirsutum, Ganoderma applanatum, Phellinus pomaceus, Schizophyllum commune, etc. Los ejemplares de ciruelo de Pissard presentan, además, gomosis;

* Eryophies salicis, en la totalidad de los sauces; 
* diversos agentes actúan sinérgicamente con la contaminación. Las podas defectuosas, ciertas acciones vandálicas y la excesiva densidad de las plantaciones favorece la dispersión de enfermedades y la muerte de árboles dominados; pueden observarse oidios en el follaje de árboles bajos, además de en espinos, mahonias, fotinias y otros arbustos.
En total se han hallado 1.185 pies con fumaginas, 1.326 con depósito de partículas sólidas, 1.231 chopos con Cytospora chrisosperma, 390 cipreses con chancro del ciprés, 105 frondosas con daños necróticos en tronco, entre otras patologías. Se han clasificado 4.741 coníferas como sanas y 4.211 como enfermas, mientras que 6.701 frondosas aparecen sanas y 3.022 enfermas.

\section{REFERENCIAS}

(1) Adams, D.D.; Page W.P. Acid deposition. Environmental. economic and policy issues. Plenum Press, New York.1985.

(2) Adams, M.B. \& O'Neil, E.G. Effects of ozone and acidic deposition on carbon allocation and mycorrhizal colonization of Pinus taeda L. seedlings. Forest Science, 37 (1): 5-16. 1991.

(3) Anónimo. Recoqnition of air Pollution injury to vegetation. Pollution Control Association, Pittsburg. 1970.

(4) Anónimo. Methods for sampling and analysis of red spruce data. In: Acid deposition. Lonq Term Trends. National Academy Press, Washington. 1986.

(5) Anónimo. Manual de Plantaciones en el entorno de la carretera. Ministerio de Obras Públicas y Transportes, Madrid. 1992.

(6) Bazzaz, F.A. \& Fajer, E.D. La vida de las plantas en un mundo enriquecido en $\mathrm{CO}_{z^{-}}$Investigación $y$ Ciencia, marzo 1992: 6-13.

(7) Frits, H.C. The rins and climate. Academic Press, Londres. 1971.
(8) Kasuya, M.C.M. \& Muchovej, R.C.M. Temperature effects on mycorrhizal formations of Pinus caribaea var. hondurensis. South African Forestry Journal 151: 32-34. 1989.

(9) Seoanez, M. La contaminación agraria, 230-233 pp. Instituto Nacional de Investigaciones Agrarias, Madrid. 1978.

(10) Smith, W.H. Air pollution and Forests. Interactions between air contaminants and forest ecosystems. Springer-Verlag, Berlin- New York. 1981.

(11) Smith, W.H. The atmosphere and the rhizosphere: Linkages with potential Significance for Forest Tree Health. In: Mechanisms of forest response to acidic deposition. A.A. Lucier, S.G. Haines, Eds. Springer-Verlag, Berlin. 1990.

(12) Tomlinson, G.C. 1990. Effects of acid deposition on the forests of Europe and North America. CRC Press. Boca Raton, EE.UU. 1990.

(13) Wark, K. \& Warner, C.F. Contaminación del aire. Limusa, México. 1990 